\title{
Questes
}

vestes Revue pluridisciplinaire d'études médiévales

$10 \mid 2006$

Croire

\section{Croire : éléments bibliographiques}

Julien Abed et Andrea Martignoni

\section{(2) OpenEdition}

Journals

Édition électronique

URL : http://journals.openedition.org/questes/321

DOI : 10.4000/questes.321

ISSN : 2109-9472

\section{Éditeur}

Les Amis de Questes

\section{Édition imprimée}

Date de publication : 15 novembre 2006

Pagination : 44-47

ISSN : 2102-7188

\section{Référence électronique}

Julien Abed et Andrea Martignoni, «Croire : éléments bibliographiques », Questes [En ligne], 10 | 2006, mis en ligne le 01 janvier 2014, consulté le 15 septembre 2020. URL : http://journals.openedition.org/ questes/321 


\title{
Choix bibliographique
}

\author{
Julien ABED, Andrea MARTIGNONI
}

AlBERT, Jean-Pierre, «Croire et ne pas croire. Les chemins de l'hétérodoxie dans le Registre d'Inquisition de Jacques Fournier », Heresis, 39, 2003, p. 91106.

AleXANDRE-BIDOn, Danièle, « Une foi en deux ou trois dimensions ? Images et objets du faire croire à l'usage des laïcs », Annales HSS, 53, 6, 1998, p. 11551190.

AleXANDRE-BIDOn, Danièle, « Des femmes de bonne foi. La religion des mères au Moyen Âge ", dans La religion de ma mère. Les femmes et la transmission de la foi, sous la direction de Jean DelumEAu, Paris, Cerf, 1992, p. 91-122.

BERIOU, Nicole, «Femmes et prédicateurs : la transmission de la foi aux XII ${ }^{\mathrm{e}}$ et XIII ${ }^{\mathrm{e}}$ siècles ", dans La religion de ma mère. Les femmes et la transmission de la foi, sous la direction de Jean Delumeau, Paris, Cerf, 1992, p. 51-70.

BoureaU, Alain, « La croyance comme compétence. Une nouvelle histoire des mentalités », dans Critique, 529-530, 1991, p. 512-526.

Boureau, Alain, "Foi », dans Dictionnaire raisonné de l'Occident médiéval, sous la direction de Jacques LE GofF et Jean-Claude SchmitT, Paris, Fayard, 1999, p. 422-434.

BOZOKY, Edina, «Les démons et les morts. Croyances et pratiques pour protéger les morts contre les démons au Moyen Âge », dans Enfer et paradis. L'au-delà dans l'art et la littérature en Europe (Cahiers de Conques, 1), Conques, 1995, p. 311-331.

Camelot, Pierrre-Thomas, "Credere Deo, Deum, in Deum», Revue des sciences philosophiques et théologiques, 30, 1941-1942, p. 149-155.

CAnadé SaUtman, Francesca, La religion du quotidien. Rites et croyances populaires de la fin du Moyen Âge, Florence, L. S. Olschki, 1995. 
CHRISTIN, Olivier, Les yeux pour le croire : les Dix commandements en images, Paris, Seuil, 2003.

DiNZELBACHER, Peter, "Étude sur l'incroyance à l'époque de la foi », in Revue des sciences religieuses, 73, 1, 1999, p. 42-79.

Dubost, Francis, Aspects fantastiques de la littérature narrative médiévale (XII - XIII siècles). L'Autre, l'Ailleurs, l'Autrefois, Paris, Champion, 1991 (2 vol.).

Faire croire. Modalités de la diffusion et de la réception des messages religieux $d u X I I^{e}$ au $X V^{e}$ siècle, Table ronde organisée par l'École française de Rome (Rome, 22-23 juin 1979), sous la direction d'André VAUCHEZ, Rome, École française de Rome, 1981.

FEBVRE, Lucien, Le problème de l'incroyance au XVI siècle. La religion de Rabelais, Paris, Albin Michel, 2003 (1942).

FERLAMPIN-ACHER, Christine, "Le croire et le cuidier », dans l'introduction à Fées, bestes et luitons. Croyances et merveilles, Paris, Presses de l'Université de Paris-Sorbonne, 2002, p. 19-28.

GERMAIN, René, «Les représentations de la Vierge, expression de la foi au Moyen Âge », dans Le culte de la Vierge, Saint-Étienne, Université Jean Monnet, 1997, p. 75-83.

GRELLARD, Christophe, Croire et savoir : les principes de la connaissance selon Nicolas d'Autrécourt, Paris, Vrin, 2005.

KRYNEN, Jacques L'empire du roi. Idées et croyances politiques en France, $X I I I^{e}-X V^{e}$ siècle, Paris, Gallimard, 1993.

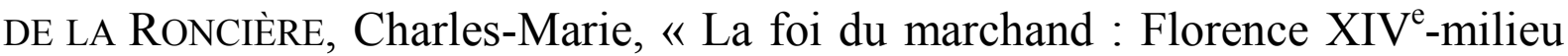
$\mathrm{XV}^{\mathrm{e}}$ siècle », dans Le marchand au Moyen Âge, Actes du XIX ${ }^{\mathrm{e}}$ congrès de la SHMES, Reims, juin 1988, SHMES et Cid édition, 1992, p. 237-250 [maintenant dans ID., Religion paysanne et religion urbaine en Toscane (c. 1250-c.1450), Aldershot, Variorum, 1994, p. 246-247].

LAURENDEAU, D., "Une démarche religieuse réfléchie : le doute dans les témoignages des déposants du tribunal d'Inquisition de Pamiers ", dans Le petit peuple dans l'Occident médiéval. Terminologies, perceptions, réalités, Actes du Congrès international, Université de Montréal, 18-23 octobre 1999, sous la 
direction de Pierre Boglioni, Robert Delort et Claude Gauvard, Paris, Publications de la Sorbonne, "Histoire ancienne et médiévale - 71, Université Paris I », 2002, p. 569-578.

LAVIS, Georges, "La concurrence entre penser, cuidier et croire chez Chrétien de Troyes », dans Marche romane, 1973, p. 147-169.

LEMAÎTRE, Nicole, "L'éducation de la foi dans les paroisses du XVI ${ }^{\mathrm{e}}$ siècle », in L'encadrement religieux des fidèles au Moyen Âge jusqu'au Concile de Trente : la paroisse, le clergé, la pastorale, la dévotion, Actes du $109^{\mathrm{e}}$ Congrès national des sociétés savantes, Dijon, 1984, Section d'histoire médiévale et de philologie, Paris, Comité des travaux historiques et scientifiques, 1985, p. 429-440.

MADERO, Marta, «Façons de croire. Les témoins et la juge dans l'oeuvre juridique d'Alphonse X le Sage, roi de Castille», Annales ESC, 54, 1999, p. 197-218.

MARTIN, R.-M., «La nécessité de croire au mystère de l'Incarnation : témoignages et documents en parties inédits du $\mathrm{XII}^{\mathrm{e}}$ siècle », Revue thomiste, 3, 1920, p. 273-280.

PALAZZO, Eric, « Foi et croyance au Moyen Âge. Les médiations liturgiques », Annales HSS, 53, 6, 1998, p. 1131-1154.

PAYEN, Jean-Charles, "Pour en finir avec le diable médiéval ou pourquoi les poètes et théologiens du Moyen Âge ont-ils scrupule à croire au démon? », dans Le diable au Moyen Age : doctrine, problèmes moraux, représentations, CUERMA [Centre universitaire d'études et de recherches médiévales, $3^{\mathrm{e}}$ Colloque, Aix-en-Provence, 3-5 mars 1978], 1979, p. 401-425.

PrÉAUD, Maxime, Les Astrologues à la fin du Moyen Âge, Paris, Lattès, 1984.

REEVES, Marjorie, The Influence of Prophecy in the later Middle Ages. A Study in Joachimism, Oxford, Clarendon Press, 1969.

RigaUX, Dominique, «Dire la foi avec des images : une affaire de femmes ? », dans La religion de ma mère. Les femmes et la transmission de la foi, sous la direction de Jean Delumeau, Paris, Cerf, 1992, p. 71-90.

RIgAuX, Dominique, «Croire aux images. Fonctions officielles et usages non avoués de l'image peinte dans l'Italie du $\mathrm{XV}^{\mathrm{e}}$ siècle ", dans Historiens et géographes, Histoire religieuse, 2, 1994, p. 157-170. 
RUSCONI, Roberto, «La religione dei cittadini : riti, credenze, devozioni », dans Ceti sociali e ambienti urbani nel teatro europeo del '300 e del '400, Convegno di Studi del Centro Studi sul teatro medioevale e rinascimentale, Viterbe, 30 mai-2 juin 1985, sous la direction de M. Chiabò et F. Doglio, Viterbe, Union Printing, 1986, p. 259-315.

SCHMITT, Jean-Claude, « La croyance au Moyen Âge », Raison présente, 113, 1995, p. 5-22.

SchmitT, Jean-Claude, « La croyance au Moyen Âge », p. 77-96 et « Du bon usage du Credo », p. 97-126, in ID., Le corps, les rites, les rêves, le temps. Essais d'anthropologie médiévale, Paris, Gallimard, 2001.

VAUCHEZ, André, «Faire croire. Diffusions et réception du message religieux au Moyen Âge », Les Quatre fleuves, 11, 1980, p. 31-40.

WIRTH, Jean, «La naissance du concept de croyance (XII ${ }^{\mathrm{e}}-\mathrm{XVII}{ }^{\mathrm{e}}$ siècle) », dans ID., Sainte Anne est une sorcière et autres essais, Genève, Droz, 2003, p. 113176.

WIRTH, Jean, Sainte Anne est une sorcière et autres essais, Genève, Droz, 2003.

RusConi, Roberto, Profezia e profeti alla fine del Medioevo, Viella, Centro internazionale di Studi Gioachimiti, 1999.

SchmitT, Jean-Claude, "Les Superstitions", dans Histoire de la France religieuse, publiée sous la direction de Jacques LE GOFF et René RÉMOND, Paris, Seuil, 1988, vol. I, Des origines au XIV siècle, p. 416-551.

VAUCHEZ, André, Les laïcs au Moyen Âge, pratiques et expériences religieuses, Paris, Les Éditions du Cerf, 1987.

VAUCHEZ, André, Saints, prophètes et visionnaires : le pouvoir surnaturel au Moyen Âge, Paris, Bibliothèque Albin Michel Histoire, 1999.

Veyne, Paul, Les Grecs ont-ils cru à leurs mythes? Essai sur l'imagination constituante, Paris, Éditions du Seuil, 1983. 